\title{
Shandong Dongying Lijin Industrial Park Cycle Reform
}

\author{
Ying Wang ${ }^{1}$, Runzhou Wang ${ }^{1,}$ a, * \\ ${ }^{1}$ Tianjin University of Technology, Tianjin, China. \\ a455931700@qq.com
}

\begin{abstract}
In recent years, industrial parks have been quickly completed throughout the country. It has provided a platform for opening up exchanges, attracting investment, and researching high-end science and technology fields, and has comprehensively enhanced China's strength in the fields of industry, economy, and scientific research. The rapid layout of the park has also broken the balance of development, resulting in problems such as the unclear positioning of the industry, low correlation between the industrial chains, lack of technological innovation, the inability to develop a sustainable circular economy, and unreasonable land-use planning. This study will analyze the problems existing in most industrial parks, and understand the current situation and trends of recycling in the parks at home and abroad. Then we will conduct an example analysis of Denying Lijiang Development Zone in Shandong Province and adopt relevant industrial engineering methods. Efforts will be made to increase the utilization rate of resources and strengthen the correlation between industries so as to realize the recycling of industrial parks.
\end{abstract}

Keywords: Industrial park, Recycling, Park transformation, Industrial Engineering.

\section{Introduction}

Most industrial parks in China are now built after the reform and opening up. According to the "China Development Zone Auditing Announcement Catalogue (2006)", so far there are more than 1,500 various industrial parks in China [1].This includes about 200 national parks, more than 88 national high-tech zones, and more than 1,200 provincial-level parks. In China, all provinces, autonomous regions, and municipalities directly under the central government are excluded from Tibet [2].Although various types of parks under the county level, townships, and towns under the provincial level have not yet had detailed statistical data, there are a large number of such parks distributed in various regions within China. In addition, a large number of industrial parks centered on large-scale enterprises are also deployed in China. According to the analysis of relevant associations, the total industrial output value of development zones above the provincial level, as well as functional zones, agglomeration zones, and industrial concentration zones in the provinces can account for more than $60 \%$ of the country[3],thus becoming an important guarantee for China's economic development. While manufacturing industrial output value and social wealth, the park is also a region where resources and energy consumption and environmental pollution are relatively serious in China.

Reviewing the development process of China's industrial parks can basically be divided into three processes: The first process is the economic and technological development zone, which focuses on the development of economic output value. The main features are enclosures and blind industry aggregation, and most industries have not grown up. The second process is a high-tech industrial development zone, focusing on the development of sophisticated technologies, with emphasis on industrial planning as the main feature, and the introduction of many high-tech enterprises; the third process is an eco-industrial park and circular economy park, in order to achieve resources - The overall efficiency of the environment-economy. These developments are all transformations and enhancements of existing parks [4].

This is consistent with the four criteria proposed by scholar Korhonen for the development of circular parks: The first is to follow the principle of diversity, which involves the variety of products produced by enterprises, the types of waste materials between companies, and the types of byproducts that remain diverse to ensure the eco-industrial park The second is the principle of recycling, which points out that energy cascade utilization and resource recycling are two; the third is the principle of rationality. It needs to consider the local environmental carrying capacity, make full use 
of the special resources of the area where the park is located, and adapt the production conditions to local conditions. The fourth is the principle of mutual tolerance, which integrates the human industrial system into natural ecosystems and uses resource-environment-economic complementarities to link the natural ecosystem's operating cycle in the human industrial system [5].

In China, most of the establishment of eco-industrial parks and circular economy industrial parks is hosted by the government, with the market as the main body and the park being implemented. The main difference between the two parties is that the driving departments are not the same. The construction methods are different, but the ultimate goal is same.

\section{Method}

Strengths Weaknesses Opportunities Threats: strategic management is the art and science of formulating, implementing, and evaluating cross- functional decision- making that enables organizations to achieve their goals. The process includes three phases: strategy formulation, strategy implementation, and strategic evaluation. In the first phase, the "strengths- weaknessesopportunities- threats (SWOT) matrix" is one of the important matching tools for strategy development. The key lies in matching internal and external important factors so as to effectively establish alternative strategies [6].

Strengths:

Traffic location advantages: Lijiang is located in the hinterland of the Yellow River Delta and the Blue Economic Zone of Shandong Peninsula. The traffic is convenient. Three provincial highways, Xin he, Binging and Pyongyang, cross the border. Lijiang County crosses the Ringwood and Dogging Expressways and the Tonging Railway. , Victory, Denying two cross-Yellow River Bridge were built, adjacent to the state-level cargo port Denying Port, Jading Expressway is located at the southern end of the industrial park, two hours' drive from the Jading Peninsula and Beijing-Tianjin-Hebei economic circle, forming a convenient network Big traffic pattern.

Weaknesses:

Industrial concentration is not high: At present, both the scale of the leading enterprises for renewable resources, the type and quantity of waste resources gathered, and the amount of resource utilization are relatively low, and they need to be further improved. The number of enterprises with radiation influence on the periphery is insufficient, and it is not possible to make good use of various exhaust gas wastes from the recovery of surrounding enterprises to help them achieve recycling reduction, which will play a leading role in demonstration. Waste recycling rate around steel enterprises only has waste steel recycling industry chain, waste plastic recycling industry chain, waste rubber recycling industry chain and waste lubricant recycling industry chain, but there is also a lack of chemical material waste slag, waste catalyst recycling companies.

Opportunities:

Policies help boost the development of industrial parks: The Lijiang Circular Economy Industrial Park was identified as the "city mineral demonstration park" in Shandong Province and it is the only industrial park to be recognized in Denying City. The "City Mineral Demonstration Park" has enabled the park to consistently obtain preferential industrial benefits, accelerate the industrial clustering of the park, and enhance the growth of the park's recycling economy and renewable resources industry. In addition, according to the guidelines of "opening up the frame and leaving enough space", the Park Management Committee has adjusted the basic urban planning and park design.

Threats:

Financing Dilemma: The financial institutions that support the development of the Lijiang Circular Economy Industrial Park lacked "green" investment and financing, which resulted in the lack of clear guidance for the circulation of capital to industries with low pollution and high resource control rates; the construction of the park's financing system was not perfect, and enterprises lacking financing operations were There is no stable, constraining, and institutionalized circular economy investment mechanism. There is no industrial investment fund set up specifically for the development of circular economy; a single financing method does not form an incentive for diversified investment and 
financing entities to participate in the circular economy construction of Lijiang Circular Economy Industrial Park. System.

The government financing platform is not strong enough. It is more difficult to achieve full coverage of the development and construction of the entire region, and it is also not conducive to the improvement of the economic structure of the park and the transformation of development methods. Because the park does not have its own financing function, the development funds of the park mainly come from land pre-deposits of project owners and borrowings from subordinate companies to enterprises.

\section{Conclusion and Discussion}

Economic benefits: The recycling design project of the park and the adoption of projects introduced from outside will increase the overall economic output and quality of the park. Through the extension of the industrial chain and the establishment of a recycling-type industrial chain, comprehensive utilization of solid waste such as waste lubricating oil and scrap steel can be realized, and high-value-added deep processing products can be added. According to the above method, it can ensure that the resources output indicators and resource consumption indicators of the park reach the domestic advanced level. By 2025, the capital productivity of the park will increase to 2.0989 million Yuan per ton, an increase of 39\% over 2015. The energy output rate will increase to 178.44 million Yuan per ton of standard coal, an increase of $41 \%$ over 2015 . Through the implementation of the comprehensive renovation and expansion project, and the implementation of recycling projects such as centralized cogeneration of heat and power generation, by 2025, the energy consumption per unit of production of the park will drop to 0.5786 tons of standard coal per ten thousand Yuan, which is about 30\% lower than in 2015.

Environmental benefits: By 2025, the capacity of comprehensive utilization of by-products and wastes in the park will increase significantly, the proportion of service industry will increase significantly, and the characteristics of the park's recycling will become more apparent:

(1)The sewage pipeline network supporting facilities in the park are more perfect. According to the principle of "source control and standard rectification", all the sewage generated by all enterprises must reach the standard to be discharged to the sewage treatment plant in the park;

(2) Waste acid and alkali and other hazardous wastes will be treated in a centralized manner. All types of waste liquids will be classified and safely stored and stored, so as to achieve the purpose of clean environment and safe production, thus avoiding secondary environmental pollution and protecting the ecological environment;

(3)The industrial waste gas monitoring and control capacity is strengthened, and it is networked with the municipality and the district, and the whole process is supervised; the sealed land transportation rate and dust rectification control target site has to reach more than $95 \%$;

(4) To reduce or even eliminate the output and emissions of wastes and pollutants, and to increase the industrial product output and product consumption process to be compatible with the environment and reduce the risks to humans and the environment during the entire product life cycle;

Social Benefits: Through the cyclical transformation of the park, especially the introduction of external recycling projects, the construction of infrastructure such as information platforms, supporting logistics transportation and warehousing has been accelerated, and the internal circulation of resources has been formed within the park, which is conducive to further attracting investment in the park for circular economy. Promote the concept of circular economy and lay a good foundation for attracting high-tech products and projects. At the same time, the park will focus on the introduction of recycling projects. It will also greatly increase the awareness of the public, enterprises and authorities on ecological awareness and green consumption, increase the enthusiasm for protecting the ecological environment, and create a good social atmosphere. It will be a green economy and green industry in China. The development provides development experience. 


\section{References}

[1]. Qin Livia. Research on the construction mode of Jilin eco-industrial park [PhD thesis]. Jilin: Department of Environmental Science, Northeast Normal University, 2008.

[2]. China Development Zone Network. China Development Zone Network China Development Zone [EB/OL]. (2013, 03, 15) [2013, 04, 30].Http://www.cadz.org.cn/kfq/index.jsp?id=561.

[3]. Liu Honie. The current status of the development of China's eco-industrial parks: analysis based on typical eco-industrial demonstration parks. Contemporary Economics, 2011(2):52-54.

[4]. Lu Zhongwu. Foundation of Industrial Ecology. Beijing: Science Press, 2010.

[5]. Liu Yu, Tina Jinxing, et al. Study on Eco-efficiency Assessment Method of China's Comprehensive Eco-Industrial Park Based on DEA. China Population Resources and Environment, 2012 (S1):93-97.

[6]. Liu Y. Research on University's Official Microblog Development Strategy Based on SWOT Analysis [J]. Journal of Higher Education, 2018. 